Article

\title{
Exploring the Effectiveness of Multifunctional Cultivated Land Protection Linking Supply to Demand in Value Engineering Theory: Evidence from Wuhan Metropolitan Area
}

\author{
Siyu Zhang ${ }^{1}$, Weiyan $\mathrm{Hu}^{1, *}$, Liejia Huang ${ }^{2}$ and Hongjie Du ${ }^{1}$ \\ 1 College of Public Administration, Huazhong Agricultural University, Wuhan 430070, China; \\ zhangsy@webmail.hzau.edu.cn (S.Z.); dhj230@outlook.com (H.D.) \\ 2 Business School, Hubei University, Wuhan 430062, China; huangliejia@hubu.edu.cn \\ * Correspondence: huweiyan@mail.hzau.edu.cn
}

Received: 6 October 2019; Accepted: 4 November 2019; Published: 7 November 2019

check for updates

\begin{abstract}
The purpose of this paper is to analyze the effectiveness of multifunctional cultivated land protection based on the value engineering theory. The study area is the Wuhan Metropolitan Area. Entropy method, comprehensive index method, opportunity cost method and most suitable regional method were employed. The coefficients for importance of functions, for costs, and for values in production, social and ecological of cultivated land were measured. Significant spatial differences in the effectiveness of multifunctional cultivated land protection were found. According to the effectiveness of multifunctional cultivated land protection, the study area can be divided into the following three regions: the "most suitable region", where the functions of cultivated land and their costs are matched in most parts of the study area; the "optimization region for functional structure", mostly located in the Jianghan Plain, where the structure of multifunctional cultivated land needs further optimization; and the "improvement region for functional level", including the mountainous areas, such as Yingshan and Wuxue in the East, and the municipal districts, such as Wuhan and Ezhou, where the potential for improving level of multifunctional cultivated land is relatively large. The article contributes to firstly introducing value engineering theory into the research of cultivated land protection, linking demand to supply of functions of cultivated land. We suggest that different policies might be implemented to optimize the spatial layout of cultivated land protection, and to manifest and coordinate multiple functions of cultivated land. It is vital to improve the use efficiency of funds for multifunctional cultivated land protection, and in the end to realize effective protection of cultivated land in quantity, quality and ecology at a lower cost in a sustainable way.
\end{abstract}

Keywords: land economy; value engineering; match of demand and supply; efficiency analysis; multifunctional cultivated land protection

\section{Introduction}

Cultivated land is an indispensable key resource for human survival and development, which is related to food security, social stability, and ecological security [1]. Especially in China, 22\% of the world's population was fed by only 7\% of the world's cultivated land [2], and 2 million hectares of agricultural land fall out of production each year [3]. Uneven distribution and potential threats to its quality influence human wellbeing [4], which determines the importance and urgency of the protection of cultivated land. It is urgent to improve the effectiveness of cultivated land protection. In that case, the Chinese government has successively set up a series of strict cultivated land protection systems, including land requisition-compensation balance, land use control, and regulating land 
use from cultivated land to non-cultivated land, and also a series of incentive policies such as one reduction three subsidies (agricultural tax reduction, direct food subsidies, improved seed subsidies, agricultural machinery purchase subsidies), increasing agricultural investment to protect agriculture [5]. However, the effect of cultivated land protection is generally low and far from the expected goal due to only paying attention to the protection of cultivated land in quantity, and neglecting cultivated land protection in quality and in ecological [6]. Cultivated land protection is only focused on the supply level, while being ignored at the demand level [7]. Therefore, the former Ministry of Land and Resources has continued to carry out the practice of cultivated land quality evaluation since the 1990s. In 2009, it issued the results of the national cultivated land quality evaluation, and formulated the rules for classification, grading, and evaluation of agricultural land quality. In August 2016, the former Ministry of Land and Resources of the People's Republic of China issued the "Guidance on Complementing the Balance of Cultivated Land and Improving the Quality of Cultivated Land to Implement the Balance of Requisition and Compensation". In January 2017, the State Council of the Central Committee of the Communist Party of China (CPC) promulgated the "Guidance of the CPC Central Committee and the State Council on Strengthening the Protection of Cultivated Land and Improving the Balance of Requisition and Compensation". These documents reemphasize the importance of cultivated land resources and require strict implementation of the cultivated land requisition-compensation balance. The Chinese government has continuously optimized policies for protecting cultivated land and agriculture. According to the Year Book of Chinese Rural Statistics and the Report on Chinese Agricultural Development, since the abolition of agricultural taxes in 2004, agricultural protection production subsidies in production have increased year after year, reaching RMB 4.685 billion in 2016, but fell to RMB 0.459 billion in 2018. The subsidies for the protection and utilization of agricultural resources have increased from RMB 0.204 billion in 2010 to RMB 1.138 billion in 2018. This marks the shift from the protection of cultivated land in quantity to in quantity, quality, and ecology, and it also shows a transition from the protection of cultivated land in physical to in function.

Cultivated land has multiple functions in production, social culture and ecology $[8,9]$. As far as single function is concerned, cultivated land does not have absolute advantages, but it has very strong comprehensive advantages in consideration of the symbiosis and synergy of cultivated land functions [10]. However, under the condition of limited investment in cultivated land protection, there is a certain degree of subordination among the functions of cultivated land [11]. The manifestation and expression of cultivated land function is relative to human needs. When the society develops to a certain stage, it needs the cultivated land to provide corresponding functions. Humans also meet their own functional needs through modern engineering and technical means [7]. Therefore, how to balance and optimize the production, social, and ecological functions of cultivated land at a lower cost, how to match the supply and demand of multi-function cultivated land and improve the effectiveness of cultivated land protection has become an important proposition of current cultivated land protection.

Many scholars have done a lot of research on the effectiveness of the protection and conservation of cultivated land, landscape, water, soil, and natural resources. From the perspective of supply, the effects of cultivated land protection in quantity were measured by Data Envelopment Analysis (DEA) [12], and some scholars developed models to evaluate the effectiveness of three soil and water conservation countermeasures in quality [13]. Considering the economic costs, some scholars used cost-benefit analysis and Farrell's method to analyze the effectiveness of the cultivated land protection program, assessed changes in land use damage to the environment, and calculated the value of the ecological network in order to obtain an optimal strategy for natural resource protection [14-17]. From the perspective of demand, research focuses on the performance of cultivated land and other natural resource conservation projects or policies by measuring willingness to pay or farmers' satisfaction [18-20]. In summary, the existing research on cultivated land protection efficiency focuses on quality and quantity, the effectiveness and spatial difference analysis of cultivated land protection from functional level is still lacking. The existing research studies the protection efficiency of cultivated land and other natural resources from the perspective of supply and the perspective of 
demand, and gradually considers the economic cost in the research process. However, the research on cultivated land protection from the perspective of matching supply and demand is in its infancy.

The matching of supply and demand is an important prerequisite for improving efficiency [21], and effective supply chain management is important for meeting the existing demand. This is reflected in various fields, such as passenger transportation, freight transportation, and shipping, and it is particularly important in cultivated land protection [22-24]. Value engineering is a systematic method, which focuses on the realization of the functions that meet demand at a lower life cycle cost [25]. Thus, in this article, based on the value engineering theory, we established a linkage mechanism between the demand and supply of cultivated land functions. Taking the county scale of the Wuhan Metropolitan Area as an example, we analyzed the effectiveness and spatial difference of multifunctional protection of cultivated land by measuring the value coefficient of multifunctional cultivated land protection in the study area, trying to provide a basis for the spatial optimization of cultivated land. The structure of this paper is as follows: this section introduces the background and literature review; Section 2 introduces a theoretical framework and research methods; Section 3 is the study area and data recourse; Section 4 reports the research results. The final section is the discussion and conclusion.

\section{Theoretical Framework and Methods}

\subsection{Theoretical Framework}

In the practice of purchasing materials during World War II, American engineer Myers found that the procurement of materials is not the procurement of the material itself, but the function of the purchased materials. Therefore, a scientific organization technology and management method was proposed, which systematically analyzes the function of the research object and effectively increases the value of the research object with a lower life cycle cost. This method, called value engineering or value analysis, has been widely used in the fields of industrial production [26,27], architectural design, and construction [28,29]. In recent years, it has gradually expanded to tourism resources [30], environmental protection [31], and resource recovery [32]. The core of cultivated land protection is to protect cultivated land and improve the multifunctional value of cultivated land. Thus, this paper applies value engineering to the validity analysis of multifunctional protection of cultivated land. The basic principle is as follows:

$$
V_{i}=F I_{i} / C I_{i}
$$

where $V_{i}$ is the value (coefficient), which is a comprehensive evaluation of the functional requirements and cost matching of cultivated land, that is, the ratio of the necessary functions of cultivated land to the total cost of the cost relative to human demand; $F I_{i}$ is the importance coefficient of multifunctional cultivated land; $C I_{i}$ is the multifunctional cultivated land protection cost coefficient which is the necessary input to meet the specific functions of cultivated land to protect cultivated land. Specifically, according to the research needs, the cost of cultivated land protection is divided into two parts: opportunity cost and input cost.

The function of cultivated land is mainly reflected in the two aspects of supply and demand. The function referred to in the article is the function at the demand level. Human beings need cultivated land to provide corresponding functions, or to meet their own functional needs through modern engineering techniques. According to Maslow's demand theory, human needs for cultivated land protection mainly include four levels. The first level is the demand for survival, which is manifested by the demand for food production and basic production materials. These needs are met by the production function of grain and cash crops in cultivated land. The second level is security needs, including current security and future security. Health security, economic security, and food security constitute realistic security, which is realized through the function of producing economic benefits of cultivated land and ensuring food security, basic life, and employment. Land security and ecological security constitute future security. Cultivated land supports and maintains the functions of the human living environment, such as climate regulation, water conservation, soil and water conservation, soil fertility 
renewal and maintenance, nutrient cycling, carbon dioxide fixation, and other functions to ensure future security. The third level and the fourth level are the emotional needs and development needs, including the inheritance of farming culture, the needs of cultivated land leisure sightseeing, and the embodiment of the sustainable development concept in the protection of cultivated land resources, which belong to higher level requirements [10]. Considering the two basic needs of survival demand and safety demand, starting from the demand of cultivated land protection, we systematically collated the various functions of cultivated land, and established the following functional system diagram (Figure 1).

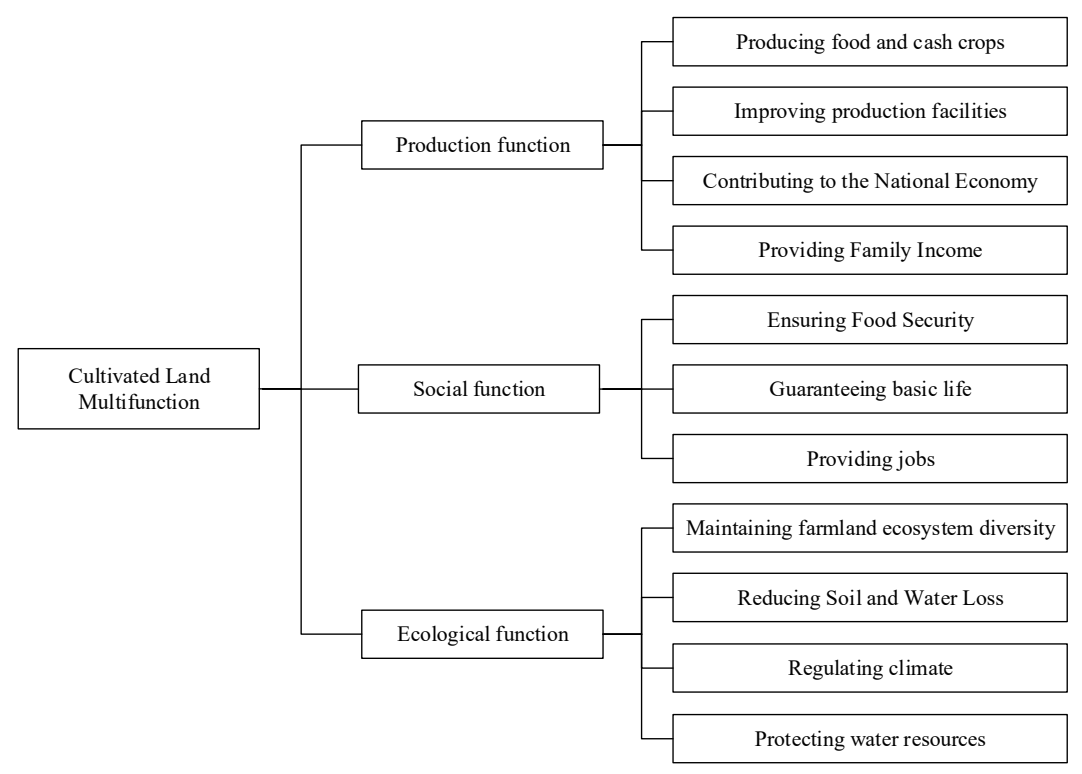

Figure 1. System map of multifunctional cultivated land.

According to the abovementioned value engineering theory and multifunctional cultivated land theory, using the following research methods, first of all, we established a multi-function evaluation index system of cultivated land and determined the weight of indicators, calculated the weighted score of functional indicators, evaluated the various functions and functions of cultivated land, and further calculated the cultivated land importance coefficient. Secondly, considering the input cost and opportunity cost, the multifunctional protection cost of cultivated land and the multifunctional protection cost coefficient of cultivated land were calculated. Then, the ratio of the functional importance coefficient of the cost coefficient was calculated to obtain the multifunctional protection value coefficient of cultivated land. Finally, we analyzed the effectiveness of multifunctional cultivated land protection.

\subsection{Evaluation Method of Cultivated land Multifunction}

Considering the two basic needs of survival demand and safety demand, we divided the cultivated land function into three functions: production function, social function and ecological function. Referring to relevant research [8,33-35], combined with the current situation of cultivated land use in the Wuhan Metropolitan Area and the possibility of data, a multi-level evaluation index system of cultivated land composed of 12 indicators was established (Table 1). The process of data processing was as follows: 
Table 1. Evaluation system of multifunctional cultivated land in the Wuhan Metropolitan Area.

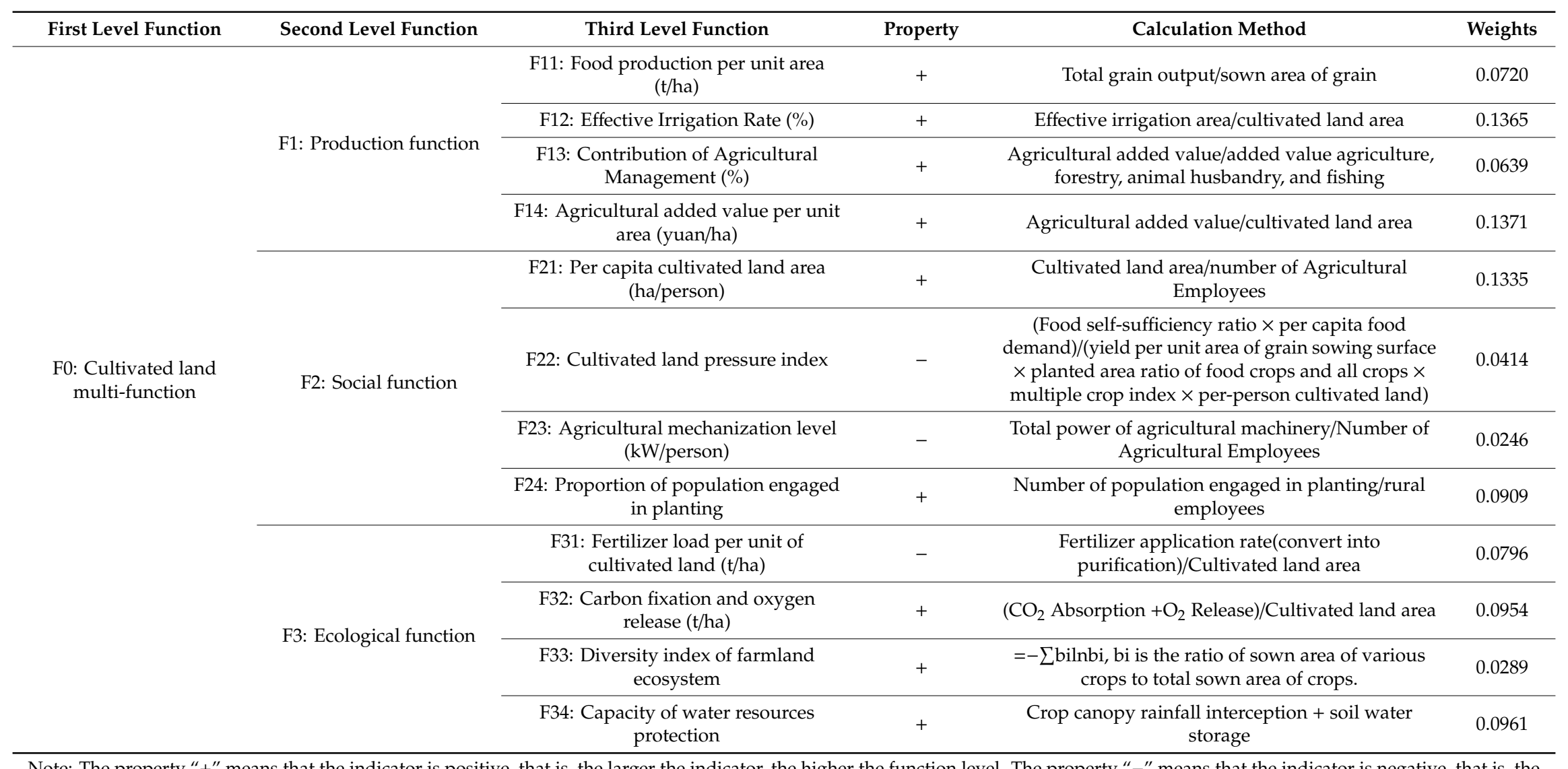

Note: The property " + " means that the indicator is positive, that is, the larger the indicator, the higher the function level. The property " - " means that the indicator is negative, that is, the larger the indicator, the lower the function level. Value of weights is determined by the following Entropy method. 
(1) Standardization of indicator data. Because of the differences in index dimension, the range transformation method was used to standardize the processing. The formula for calculating the positive index was as follows:

$$
X_{i j}=\frac{x_{i j}-\min \left(x_{i j}\right)}{\max \left(x_{i j}\right)-\min \left(x_{i j}\right)} .
$$

The formula for calculating the negative index was as follows:

$$
X_{i j}=\frac{\max \left(x_{i j}\right)-x_{i j}}{\max \left(x_{i j}\right)-\min \left(x_{i j}\right)},
$$

where $x_{i j}$ is the original indicator value and $X_{i j}$ is the normalized index value.

(2) Determining indicator weights. Entropy method is an objective weight determination method, which determines the weight according to the degree of correlation between the indicators and the amount of information they contain. This method can eliminate the artificial subjective influence and overlap of information between multiple indicators to a certain extent, so we used it to determine the weight of indicators [36,37]. The calculation formula is shown in Equation (4):

$$
w_{i j}=\frac{1-e_{j}}{n-\sum_{i=1}^{n} e_{j}} .
$$

In the equation, $e_{j}=-\frac{1}{\ln m} \sum_{i=1}^{m} P_{i j} \ln P_{i j}, P_{i j}=\frac{X_{i j}}{\sum_{i=1}^{n} X_{i j}}, n$ is the number of evaluation indicators, $m$ is the number of evaluation units, $e_{j}$ is the entropy of the $j$ th indicator, $P_{i j}$ is the proportion of the standardized value of the $i$ th evaluation unit index in the $j$ th index to the entire evaluation index sequence, and we assume that when $P_{i j}=0, P_{i j} \times \ln P_{i j}=0 . w_{j}$ is the weight value of the $j$ th indicator.

(3) Calculating the weighted score of the evaluation index. The weighted score of each evaluation index was calculated by the comprehensive index model method. The calculation formula is shown in Equation (5):

$$
F_{i}=\sum_{j=1}^{n} X_{i j} \times w_{i j},
$$

where $F_{i}$ is the weighted score of the cultivated land function of the $i$ th evaluation unit. We calculated the production function index, social function index, ecological function index of cultivated land and cultivated land multifunction index.

(4) Measuring coefficient for importance of multifunctional cultivated land. On the basis of indexes of production, social, and ecology, and multifunctional indexes of cultivated land, the coefficient for importance of multifunctional cultivated land was measured according to Equation (6):

$$
F I_{i}=F_{i} / \sum_{i=1}^{m} F_{i} .
$$

The meaning of the letters in formula (6) is the same as mentioned above.

\subsection{Methods for Calculating the Cost of Multifunctional Cultivated Land Protection}

The cost of multifunctional cultivated land protection refers to the necessary inputs for cultivated land protection to achieve specific functions of cultivated land, including the input cost and opportunity cost of cultivated land protection [38]. The input cost was the human and capital input of the cultivated land protection implementers, including the direct use for cultivated land consolidation, cultivated land restoration, the development of an irrigation system, and soil improvement. Investment in agricultural science and technology innovation and cultivated land ecological protection was also 
included. Opportunity cost was the economic loss caused by the cultivated land protection and the inability to use cultivated land in areas with better economic benefits.

Among the various ways of land use, construction land has the highest income. To ensure food security, the government has strictly controlled the use of basic farmland. We calculated the difference between the net income of converting cultivated land into construction land and the income of using cultivated land for grain production, that is, the opportunity cost of multifunctional protection of cultivated land [38]. The calculation formula is shown in Equation (7):

$$
\mathrm{OCL}=\mathrm{CLI}-\mathrm{GLI}
$$

where OCL is the opportunity cost of cultivated land protection each year; CLI is the net income from converting cultivated land into construction land each year; GLI is the net income of cultivated land used for grain production each year. The net income obtained from converting cultivated land to construction land comes from the basic transfer fee of construction land in last-grade cities and towns, which is converted into annual net income according to the income reduction method. The net income of cultivated land used for grain production is equal to the total income minus the total cost. Its statistical data were obtained directly from the National Collection of Cost-Benefit Data of Agricultural Products.

The cost of multifunctional protection cultivated land in the Wuhan Metropolitan Area was obtained by using the method mentioned above, and the cost coefficients of corresponding functional protection were calculated according to Equation (8):

$$
C I_{i}=C_{i} / \sum_{i=1}^{n} C_{i},
$$

where $C I_{i}$ is the cost factor and $C_{i}$ is the cultivated land protection cost of the ith evaluation unit. We separately measured the input costs of cultivated land production, social and ecological function protection, and total input costs of cultivated land multifunctional protection. We also measured the opportunity cost of multifunctional cultivated land protection.

\subsection{Value Coefficient Measurement and Effectiveness Analysis of Cultivated Land Multifunctional Protection}

According to the above research method, we calculated the coefficient of cultivated land function importance and the corresponding cost coefficient. Furthermore, according to Equation (1), the value coefficient of multifunctional cultivated land protection was calculated. Suppose there is a linear value standard line, with the horizontal axis as the cost factor and the vertical axis as the function importance factor, it is a diagonal line with an angle of 45 degrees to the coordinate axis. When the value coefficient is equal to 1 , the value coefficient point of the evaluation unit is on the standard line. It was shown that the multifunctional cultivated land protection was effective. When the value coefficient was greater than 1 , the evaluation unit value point was at the top left of the standard line. It was shown that a higher level of functionality was achieved with a defined cost commitment. When the value coefficient was less than 1 , the evaluation unit value coefficient point was at the bottom right of the standard line. It was shown that protecting a given level of functionality requires a higher cost. The "most suitable region" method was proposed by Professor Tanaka of the University of Tokyo at the International Academic Symposium organized by the Society of American Value Engineers in 1973. Considering the nonlinear relationship between function and cost, we used the "most suitable region" method [39] to analyze the effectiveness of cultivated land multifunctional protection. The best suitable region consists of two hyperbolas [31]: $C=\sqrt{f^{2}-2 S}$ and $f=\sqrt{C^{2}-2 S}$, which surround the value standard line $(\mathrm{V}=1)$ and face the coordinate origin. $S$ is calculated by the empirical formula $\mathrm{S}=\frac{\sum_{i=1}^{n}\left|F I^{2}-C I^{2}\right|}{2 n}$. We set the names of the top left and bottom right of this region to "functional structure optimization region" and "functional level improvement region". Based on this method, we divided 
the research unit into three regions: (1) Region I (the most suitable region). The coefficient of the cultivated land function importance of the evaluation unit in this region is approximately equal to the cost coefficient. The cultivated land function and cost of these evaluation units are matched; (2) Region II (optimization region for functional structure). The cultivated land function coefficient of the evaluation unit in this region is greater than the cost coefficient. This can be caused by two reasons: first, the evaluation unit has played a higher level of functionality at a lower cost; another possibility is that the function of cultivated land manifestation in the evaluation unit does not meet the necessary functional requirements, and the actual input cost is not the cost of achieving the necessary function; (3) Region III (improvement region for functional level). The coefficient of cultivated land function importance of the evaluation unit in this region is less than the cost coefficient. In order to protect the functions of cultivated land, the input cost is high. In the case of controlling the input cost, it is necessary to increase the quantity level of multifunctional cultivated land.

\section{Study Area and Data}

\subsection{Study Area}

According to the United Nations Economic and Social Development World Urbanization Outlook 2014, more than half of the urban population currently lives in large cities with populations of more than 500,000 [40]. This shows that metropolitan has become a new stage of development in the process of urbanization in the world. In China, the Wuhan Metropolitan Area is an important part of the Yangtze River Economic Belt, and it is located in the central east of Hubei province, middle reaches of the Yangtze River, which consists of the capital city, Wuhan, and 48 other counties within $100 \mathrm{~km}$ around Wuhan, like Huangshi, Xiaogan, Huanggang, Xianning, Xiantao et al. In 2016, the Wuhan Metropolitan Area was $57,800 \mathrm{~km}^{2}$ and half of this was flat plain. The west part of Wuhan Metropolitan Area belongs to the Jianghan Plain, which is the important commercial grain base; $30 \%$ and $20 \%$ of it is made up by hills and mountains, respectively, mostly located in the north, northeast, and south of the study area. As the pilot area of resource-saving and environment-friendly society, the location of the Wuhan Metropolitan Area has prominent advantages and abundant regional hydrothermal resources. Thus, it has become China's important agricultural production area and central development area and the focus of the Development strategy of the Yangtze River Economic Zone and the Rising of Central China Strategy. It has made the Wuhan Metropolitan Area have the most important influence on the development of Hubei province and central China (Figure 2).

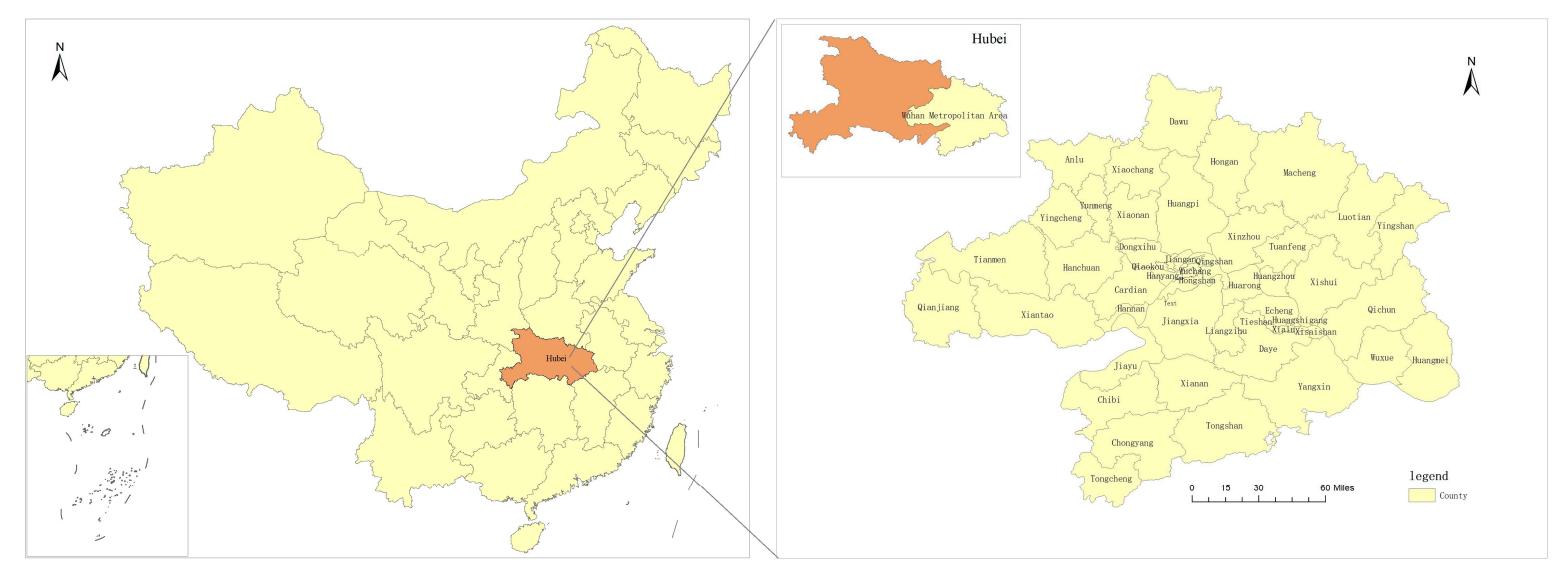

Figure 2. Location and scope of the study area.

Wuhan Metropolitan Area only accounts for 31.09\% of the total area of Hubei Province, but it houses half of the province's population and $60 \%$ of its Gross Domestic Product (GDP). With the development of new urbanization, the pressure of cultivated land protection in the Wuhan Metropolitan Area is increasing. According to the data from the Second National Land Survey, the quantity of 
cultivated land in Wuhan Metropolitan Area has declined about 7.7\% from 1995 to 2015. The scarcity of cultivated land resources will be an important bottleneck for the economic and social development of the Wuhan Metropolitan Area [41]. Hence, we chose the Wuhan Metropolitan Area as the study area, as it is important to explore a way to improve the efficiency of cultivated land protection and the method to coordinate the relationship between cultivated land protection and economic development.

\subsection{Data}

The data needed in this paper are mainly basic statistical data and annual financial data. Specifically, the data of cultivated land area, population, and crop production are from the Statistical Yearbook of Hubei Province, Hubei Rural Statistical Yearbook, Hubei Water Resources Bulletin, and the statistical yearbook of counties (cities and districts) in the Wuhan Metropolitan Area. The data of cost and income came from the official website of the Hubei Finance Department, Hubei Agricultural Department, Hubei Water Conservancy Department, and relevant departments of the local governments, as well as the National Compilation of Cost-Benefit data of Agricultural Products and Reference Land Price Query System of Hubei province.

In order to make the research comparable, this paper adjusted some urban areas of Wuhan, Huangshi, and Ezhou and divided the Wuhan Metropolitan Area into 36 evaluation units. All the data were based on 2016.

\section{Results}

\subsection{Coefficient for Importance of Multifunctional Cultivated Land}

Using the above methods, we measured the production function index, social function index, ecological function index, and multifunction index of cultivated land in 36 evaluation units of the Wuhan Metropolitan Area. Then, we calculated the coefficients for importance of production function, social function, ecological function and multifunction of cultivated land in each evaluation unit (Figure 3).

The importance of cultivated land production function is high in the center and west of Wuhan Metropolitan Area, and these area like Anlu, Yunmeng, Hanchuan, Huangpi, Caidian, and Jiangxia, mostly in Jianghan Plain, have rich soil, high irrigation guarantee rate, and superior agricultural production conditions. The areas in the eastern and southern Wuhan Metropolitan Area located in the mountainous and hill areas have low importance of cultivated land production function, such as Xian'an, Yangxin, Tongshan, Chongyang, and Hongan, etc. (Figure 3a).

The cultivated land social function level is high in the west and low in the east, and it also shows spatial differentiation with high levels in the suburbs and low levels in the urban areas (Figure 3b). Tianmen, Qianjiang, Xiantao, Anlu, Jiayu, and other areas where social function are high have better cultivated land conditions, and these areas are far from the urban areas. Using cultivated land in these areas for agricultural production can obtain a relatively stable income, so its social function level is high. The cultivated land in urban areas, such as Huangzhou, Tuanfeng, Wuhan municipal district, and Huangshi municipal district has superior location conditions, economic environment, and perfect agricultural infrastructure. It has liberated more agricultural labor, giving them more opportunities to engage in non-agricultural production, so the social function level of cultivated land is weak.

The importance of cultivated land ecological function also presents a relatively obvious spatial distribution law. For example, Macheng is surrounded by mountains on three sides, which is an important ecological barrier and has a good stabilizing effect on the water conservation capacity of cultivated land. Xiantao and Tianmen are located in the Jianghan Plain, with a wide variety of crops and a strong diversity of farmland ecosystems. Therefore, cultivated land in these areas presents high level of ecological and production functions. Huangpi district of Wuhan is one of the first agricultural tourism demonstration sites in China, and its ecological function occupies a dominant position. Huangzhou, Wuhan municipal district, and Tuanfeng are municipal districts and suburbs. In recent 
years, the economic development speed is faster and the urbanization process is accelerating (Figure 3c). The cultivated land system in these regions is fragmented because of its superior location and easily occupiable construction land, showing obvious instability, so the ecological function is insufficient.
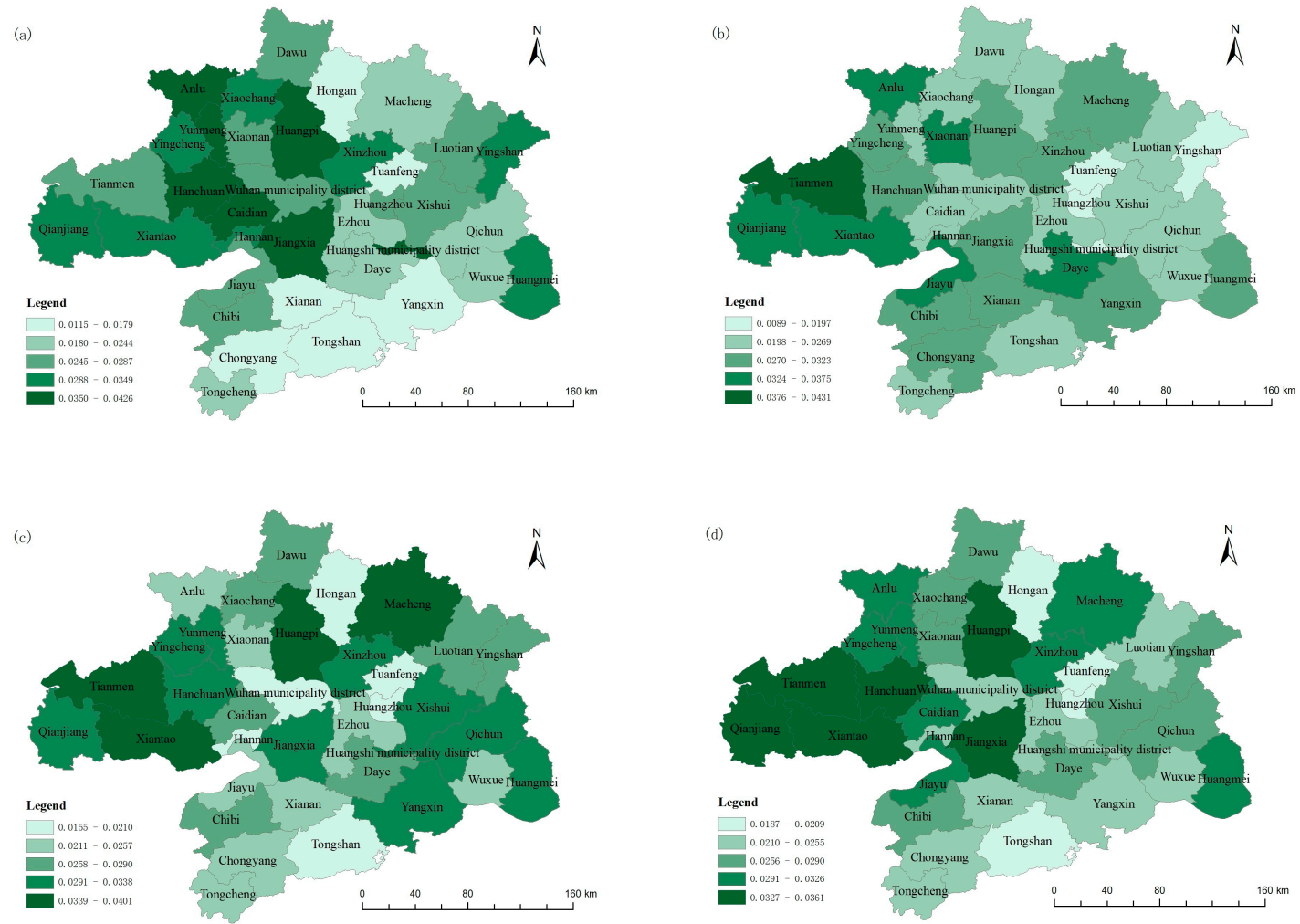

Figure 3. Coefficient for the importance of multifunctional cultivated land in the Wuhan Metropolitan Area. (a) Coefficient for the importance of production function; (b) coefficient for the importance of social function; (c) coefficient for the importance of ecological function; (d) coefficient for the importance of multifunctional cultivated land.

The spatial differentiation of the importance of multifunctional cultivated land in the Wuhan Metropolitan Area is high in the west and low in the east, and high in the north and low in the south (Figure 3d). The areas with high importance of multifunctional cultivated land are mostly in the Jianghan Plain, and the production function, social function, and ecological function can be coordinated and developed with good cultivated land condition. The areas with low importance of multifunctional cultivated land are mostly in the mountainous and hilly areas. Although the level of ecological function is high in these areas, the low production function and social function make the multifunctional cultivated land unable to manifest well.

\subsection{Coefficient for Costs of Multifunctional Cultivated Land Protection}

In recent years, the government has invested a large amount of special funds for the quantity, quality, and ecology of cultivated land protection. Specifically, agricultural support protection subsidies and basic farmland protection funds reflect the state and government investment in the protection of cultivated land production functions. Agricultural insurance premium subsidies and agricultural machinery purchase subsidies reflect the investment in the social function protection of cultivated land. Farmland water conservancy facilities construction funds and water and soil conservation comprehensive management funds reflect the protection of cultivated land ecological functions. Considering the above six special funds, we calculated the coefficient for costs of multifunctional cultivated land protection and analyzed its spatial differentiation according to Equation (8) (Figure 4). 


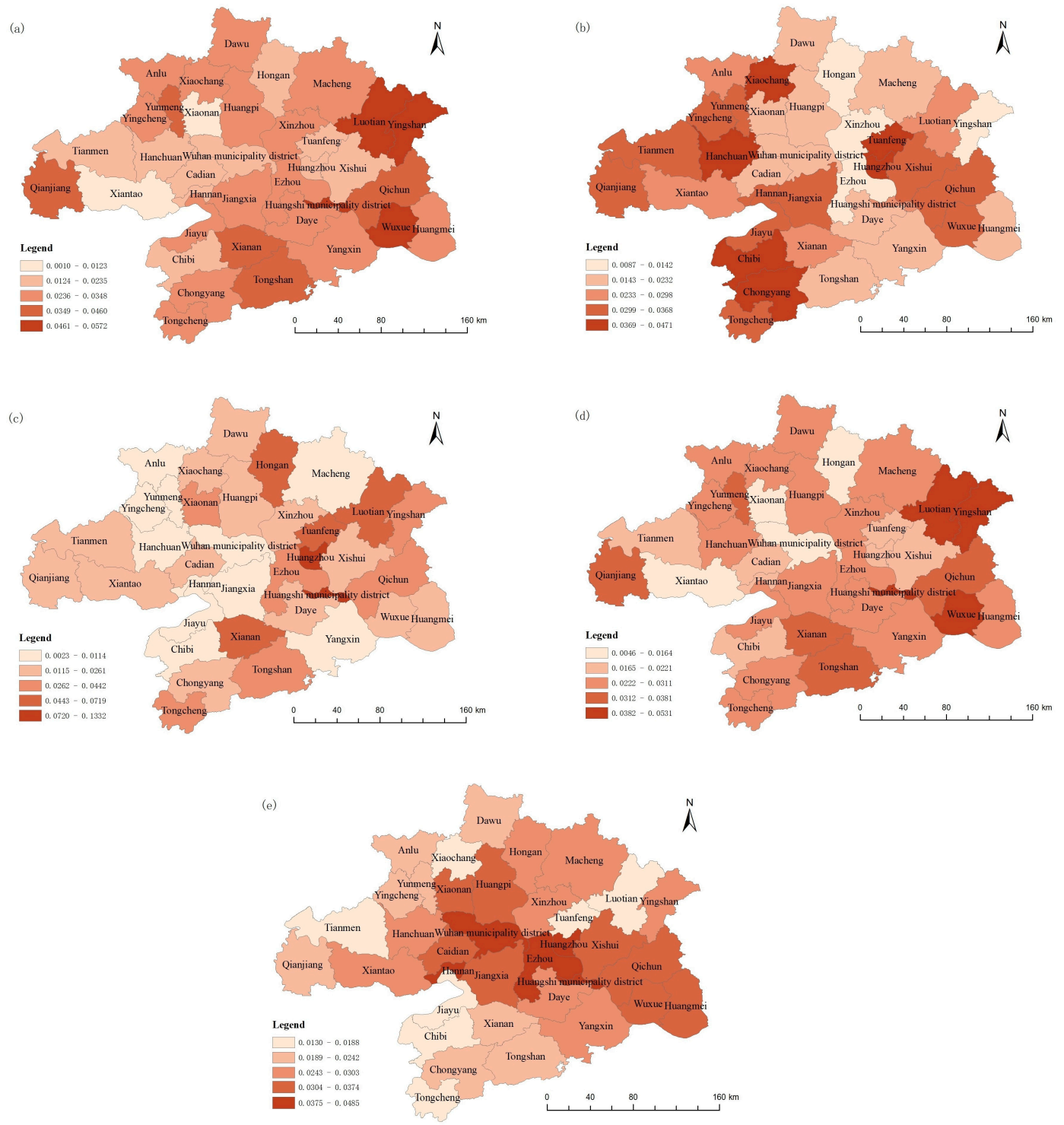

Figure 4. Coefficient for costs of multifunctional cultivated land protection in the Wuhan Metropolitan Area. (a) Coefficient for input cost of production function; (b) coefficient for input cost of social function; (c) coefficient for input cost of ecological function; (d) coefficient for total input cost of multifunctional cultivated land protection; (e) coefficient total cost of multifunctional cultivated land protection.

There are regional differences in input cost coefficients of cultivated land production function, social function and ecological function protection. The areas with higher coefficient for input cost of production function are concentrated in Luotian, Yingshan, Wuxue, and Huangshi municipal districts in the east of the Wuhan Metropolitan Area, while those in the west are relatively low (Figure 4a). The coefficient for input cost of social function in the west and southwest is higher than in the east and northeast (Figure $4 \mathrm{~b}$ ). The coefficient for the input cost of ecological function is quite different. The high value areas is mainly distributed in the central and western regions, such as Huangzhou, Huangshi municipal district, and Tuanfeng (Figure 4c). In general, the coefficient for the total input cost of multifunctional cultivated land protection in the Wuhan Metropolitan Area is higher in the east and in the south, and lower in the west and in the north (Figure 4d).

The opportunity cost of cultivated land protection is mainly the risk of constructing cultivated land, which is an important factor to measure the effectiveness of cultivated land protection [38]. Considering that the opportunity cost cannot be divided into the functions of cultivated land protection, 
we calculated the total cost coefficient based on the input cost and opportunity cost of the cultivated land multifunctional protection. The results show that coefficient total cost of multifunctional cultivated land protection presents a circle law that gradually declines in the Wuhan municipal district. The farther away from the Wuhan municipal district, the lower the total cost coefficient of cultivated land multifunctional protection, and there is a low spatial differentiation law in urban and high-suburban areas (Figure 4e).

\subsection{Effectiveness of Multifunctional Cultivated Land Protection}

Based on calculation of the coefficients for the importance of cultivated land function and the corresponding cost coefficients, we calculated the value coefficient for multifunctional cultivated land protection according to Equation (1). Based on the most suitable region method mentioned above, 36 evaluation units in the study area are divided into the "most suitable region", the "optimization region for functional structure" and the "improvement region for functional level" (Figure 5).

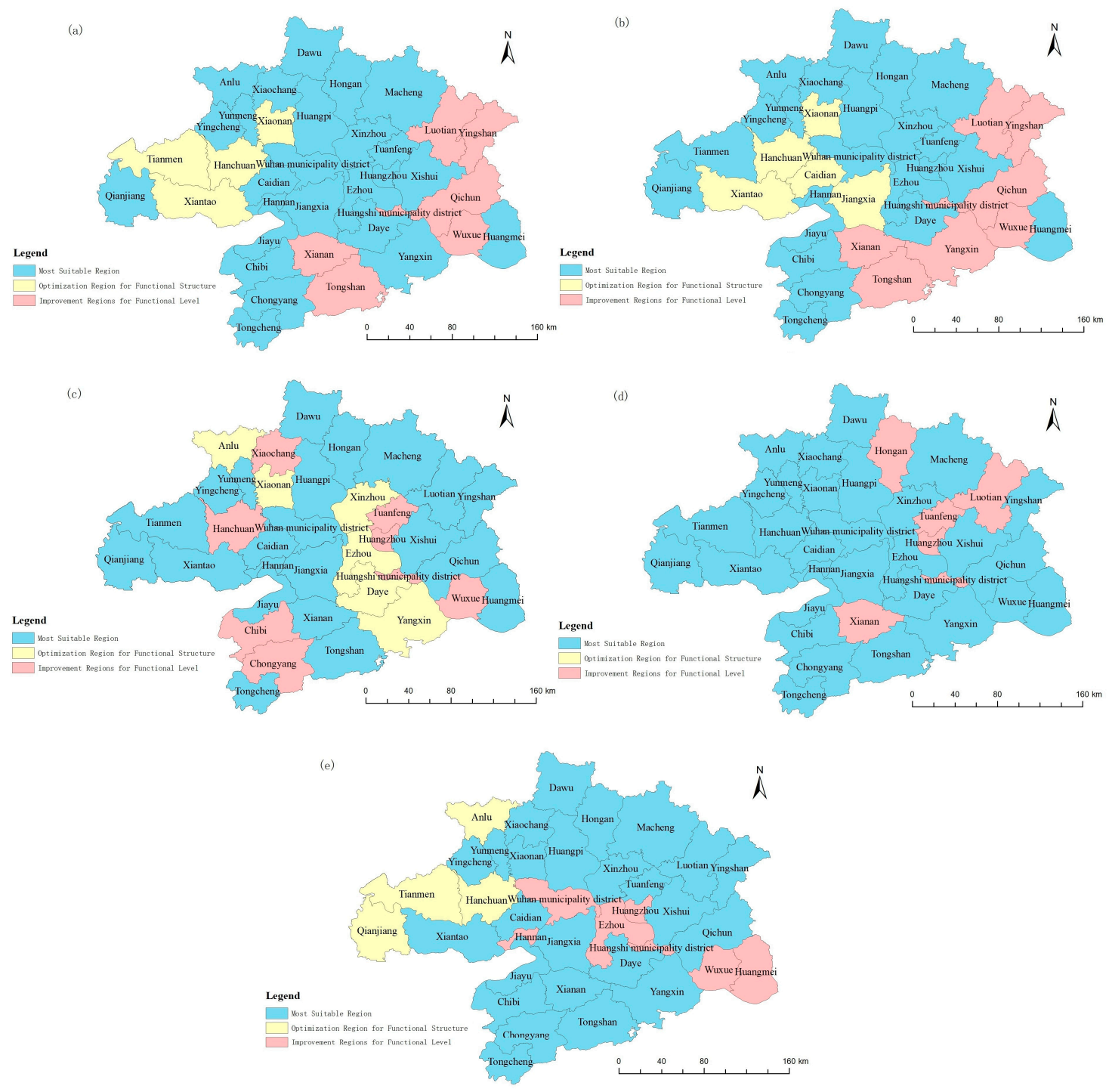

Figure 5. Effectiveness of multifunctional cultivated land protection in the Wuhan Metropolitan Area. (a) Effectiveness of multifunctional cultivated land protection (only considering input cost); (b) effectiveness of production function protection; (c) effectiveness of social function protection; (d) effectiveness of ecological function protection; (e) effectiveness of multifunctional cultivated land protection (considering both input cost and opportunity cost). 
The results show that most of the evaluation units in the study area are in the most suitable region considering the input cost (Figure 5a). This shows that the multifunctional cultivated land protection in most areas of the study area matches the corresponding cost, which is the effective region. Based on the results of Sections 5.1 and 5.2, it is found that the coefficient for importance of multifunctional cultivated land protection in these area which are in the most suitable region is not all at a high level in the Wuhan Metropolitan Area. However, the Simpson reciprocal index in most of these areas is high, and the input cost is in a relatively middle position. (The formula of Simpson reciprocal index is $\mathrm{SRI}_{i}=\frac{1}{\sum\left(F_{i j} / N\right)^{2}}$, where $S R I_{i}$ is the Simpson reciprocal index of the $i$-th evaluation unit. The bigger the index is, the richer and more even the cultivated land function will be [42,43]; $F_{i j}$ is the $j$-th weighted score of function in the $i$-th evaluation unit; $N$ is the total score.) This shows that the effectiveness of the multifunctional cultivated land protection is related to not only the coefficient for the importance of multifunctional cultivated land protection and input cost coefficient, but also the richness and evenness of the cultivated land function. That is to say, it has a certain relationship with the multifunctional in structure.

The "optimization region for functional structure" is in the eastern part of the Wuhan Metropolitan Area, including Tianmen, Hanchuan, Xiaonan, Xiantao and so on. The value coefficients for multifunctional cultivated land protection in these areas are greater than 1 . This means that the coefficient for the importance of multifunctional cultivated land protection is higher and the input cost is lower. Combined with the one-dimensional function protection effectiveness analysis, it is found that the above evaluation units have different effectiveness in the protection of different functions in terms of one-dimensional function protection effectiveness (Figure $5 b-d$ ). For example, the effectiveness of production and social function protection are in the "optimization region for functional structure", while the effectiveness of ecological function protection is in the "most suitable region" in Xiaonan. In Hanchuan, the effectiveness of production function and social function protection is in the "optimization region for functional structure" and the "improvement region for functional level", and the effectiveness of ecological function protection is in the "most suitable region". It was found that the production function level of the areas which are in the optimization region for functional structure is in the forefront of the Wuhan Metropolitan Area, and the social function and ecological function are relatively strong. However, we found that the Simpson reciprocal index of these areas in this region is low, which indicates that there is a trade-off between the production function, social function, and ecological function protection of cultivated land in this region.

The "improvement region for functional level" is distributed in the western and southern parts of Wuhan Metropolitan Area, mainly including Luotian, Yingshan, Qichun, Tongshan and so on. The coefficient for the importance of multifunctional cultivated land protection is less than the cost coefficient. Under the condition of controlling input cost, it is necessary to improve the quantity level of multi-function cultivated land. These areas in the "improvement region for functional level" is mostly located in mountainous and hilly areas. The coefficients for the importance of production function protection are all in the "improvement region for functional level", and coefficients for importance of the social function and ecological function protection are mostly in the "most suitable region" and the "improvement region for functional level". The production, social function and multifunction level of cultivated land of these areas are at a low level in the Wuhan Metropolitan Area. The input cost of cultivated land multifunctional protection is higher than other areas in the Wuhan Metropolitan Area. Therefore, the improvement in one-dimensional function and multifunction of cultivated land and the control of input cost have great potential.

In the Wuhan Metropolitan Area, the more developed cities and towns with intensive industrial construction, such as Wuhan municipal district, Huangshi municipal district, and Huangzhou, have higher land transfer income. The risk of converting agricultural land around the town to construction land is high. Therefore, we considered both the input cost and opportunity cost, and further analyzed the effectiveness of multifunctional cultivated land protection in the Wuhan (Figure 5e). The research results show that after considering the opportunity cost, the Wuhan municipal district, Ezhou, and 
Huangzhou in the central part of Wuhan Metropolitan Area are in the "improvement region for functional level". Their coefficients for importance of multifunctional cultivated land protection are less than the cost coefficient. Most of these areas are located in the central area of Wuhan Metropolitan Area and they are urban areas. To achieve multifunctional cultivated land protection, we have to pay higher opportunity costs. In the future, we should pay attention to the control of opportunity costs. However, it should be noted that in the process of cost control, the necessary functions cannot be sacrificed.

\section{Discussion and Conclusions}

\subsection{Discussion}

Firstly introducing value engineering theory, an analytical framework linking demand to supply of multifunction of cultivated land, was formed to analyze the effectiveness of multifunctional cultivated land protection in the Wuhan Metropolitan Area, China. Significant spatial differences in the effectiveness of multifunctional cultivated land protection were found.

One of our key findings was that according to the effectiveness of multifunctional cultivated land protection, the study area can be divided into three regions, and each region has different characteristics. The reasons for the differences in the effectiveness of protection of multifunctional cultivated land in these areas are also different.

Only considering the input cost, the northern parts and most of the southern parts of Wuhan Metropolitan Area are in the "most suitable region". In this region, the importance coefficient of multifunction of cultivated land protection matches the cost coefficient and the effectiveness of multifunctional cultivated land protection is high.

Most parts of the Jianghan Plain in the west of the study area are in the "optimization region for functional structure", where the multifunctional level of cultivated land protection is relatively high, and the input cost of cultivated land protection is low. However, the value coefficient among cultivated land function in production, society, and ecology has significant differences. The value coefficient of cultivated land protection for function in production is relatively higher, while that in ecology is much lower. That is to say, cultivated land protection is characterized by one-dimensional function, not in a structure-optimized way, which is also shown by the low value of the Simpson Reciprocal Index of multifunctional cultivated land. In the Jianghan Plain, there are more than $40 \%$ cultivated land resources, an improvement in the quality of cultivated land multifunction might have great potential. Based on the matching status of functions and costs of cultivated land in this region, the functions of cultivated land should be further coordinated to improve the effectiveness of multifunctional protection of cultivated land. In addition, the input cost of multifunctional cultivated land protection can be appropriately increased to improve the richness and uniformity of various functions of cultivated land.

The "improvement region for function level" can be analyzed in the following two scenarios. (1) When only considering the input cost of multifunctional cultivated land protection, the regions is mainly located in the hilly areas of the mountains, where the level of multifunctional cultivated land in amount is low, and the input cost of multifunctional cultivated land protection is relatively high. In that case, the advantages of the ecological functions of cultivated land would be outweighed in cultivated land protection through the transformation of traditional monoculture to ecological agriculture with diversities, and at the same time, the awareness of farmers to participate in multifunctional cultivated land protection and use should be improved. (2) When considering the economic cost (the input cost plus opportunity cost), the central parts of the Wuhan Metropolitan Area is in the "improvement region for function level". In this scenario, the economic cost is very high near Wuhan City, due to the high opportunity cost for cultivated land protection, and the level of multifunctional cultivated land is relatively high. Hence, on the one hand, the amount of multifunctional cultivated land could be further improved through increasing the added value of agricultural products in an intensive way and by developing featured sightseeing agriculture, a manifestation of non-productive function of cultivated 
land. On the other hand, the economic cost would be decreased through urban land intensive use and optimization of spatial structure to relieve the pressure of cultivated land protection.

As a scientific and effective method, value engineering has been promoted in many fields, such as product manufacturing, construction engineering and so on. It is feasible and innovative to introduce value engineering into land science, which provides a new idea to study multifunctional cultivated land protection, and it has directive significance for the policy-making and implementation of cultivated land protection. The difficulties of this paper are how to use the theory of value engineering focused on function analysis from the perspectives of social need, and measuring the cost from the perspectives of the supply side. We tried to establish an analytical framework linking demand to supply of cultivated land functions to analyze the effectiveness of multifunctional cultivated land protection. However, our study also has some limitations. Firstly, we measured cultivated land functions only considering the two basic needs of survival and security. Secondly, the complex nonlinear relationship between functions was not considered enough, each research unit was only considered as a whole when measuring multi-function, and the geographical and spatial elements in each unit and between different units were not considered enough. The application of value engineering in multifunctional cultivated land still might be improved in future research. On the one hand, functional analysis of cultivated land could be done deeply through considering the emotional and developmental need for cultivated land at the smaller scale, such as at the rural community/village scale. On the other hand, it would be better if the complex non-linear relationships among multiple functions of cultivated land are in consideration, and more geographical and spatial elements considered when measuring functions. In addition, in the future, we will try to establish a mechanism to allocate different protection funds according to the different effectiveness of one-dimensional functional and multifunctional protection of cultivated land in different areas. We think this has more realistic significance for the rational distribution and utilization of cultivated land protection funds.

\subsection{Conclusions}

Analysis of the effectiveness of multifunctional protection of cultivated land is the key to the development of sustainable cultivated land protection strategies and the efficient use of cultivated land protection funds. Based on value engineering theory, at first, from the social need, we systematically combed and divided the functions of cultivated land into functions of production, social, and ecology, and built a relatively scientific index for assessing multifunctional cultivated land to measure the importance coefficient of each function. Then, the input cost opportunity costs were considered, and we measured the cost coefficient. Lastly, the value (the importance coefficient divided by the cost coefficient) was used to analyze the effectiveness of multifunctional cultivated land protection. We employed the "most suitable region" method to distinguish and analyze the spatial effectiveness of multifunctional cultivated land protection, and obtained meaningful conclusions. There are significant spatial differences in the importance of multifunctional cultivated land and cost of costs of multifunctional cultivated land protection in the Wuhan Metropolitan Area. And according to the effectiveness of multifunctional cultivated land protection, the study area can be divided into three regions. Based on the analysis of the differences and causes of the multifunctional effectiveness of cultivated land in different regions, we suggest that different policies might be implemented to optimize the spatial layout of cultivated land protection, and to manifest and coordinate multiple functions of cultivated land. We hope that this research will help improve the efficiency of the use of cultivated land protection funds, and pay more attention to the matching of supply and demand in the process of cultivated land protection. Additionally, we hope it will effectively protect the quantity, quality, and ecology of cultivated land at a lower cost, promote the multifunctional management of cultivated land in a sustainable way, and, finally, realize the sustainable development of cultivated land resources.

Author Contributions: S.Z. contributed to conceptualization, formal analysis, methodology, visualization, data curation, and the writing original manuscript. W.H. contributed to conceptualization, project administration, 
funding acquisition, reviewing and editing the manuscript. L.H. contributed to funding acquisition, reviewing and editing the manuscript, and resources. H.D. contributed to data curation, methodology, and resources. Moreover, several native English speakers contributed to paper revision before the submission this time.

Funding: This research would not have been possible without sponsorship from the National Natural Science Foundation of China (grant number 71,673,105; grant number 71,403,083) and the National Social Science Fund of China(grant number 18ZDA054).

Acknowledgments: We thank the anonymous referees for their comments on the paper. All of the errors and omissions remain our own.

Conflicts of Interest: The authors declare no conflict of interest.

\section{References}

1. Liang, C.; Penghui, J.; Manchun, L.; Liyan, W. Land Use Policy Farmland protection policies and rapid urbanization in China: A case study for Changzhou City. Land Use Policy 2015, 48, 552-566. [CrossRef]

2. Sterling, S.M.; Ducharne, A.; Polcher, J. The impact of global land-cover change on the terrestrial water cycle. Nat. Clim. Chang. 2013, 3, 385-390. [CrossRef]

3. Liu, Y.; Li, Y. Revitalize the world's countryside. Nature 2017, 548, 275. [CrossRef] [PubMed]

4. Hu, W.; Zhang, S.; Song, Y.; Liu, T.; Lin, Y. Effects of Multifunctional Rural Land Use on Residents' Wellbeing: Evidence from the Xinzhou District of Wuhan City, China. Sustainability 2018, 10, 3787. [CrossRef]

5. Liu, Y.; Qiao, L. Innovating System and Policy of Arable Land Conservation Under the New-Type Urbanization in China. Econ. Geogr. 2014, 34, 1-6. (In Chinese)

6. Song, W.; Pijanowski, B.C. The effects of China's cultivated land balance program on potential land productivity at a national scale. Appl. Geogr. 2014, 46, 158-170. [CrossRef]

7. Kong, X.; Zhang, B.; Wen, L.; Hu, Y.; Lei, M.; Yao, J.; Xin, Y. Theoretical Framework and Research Trends of Cultivated Land Quality based on Elements-Process-Function. China Land Sci. 2018, 32, 14-20. (In Chinese)

8. Song, X.; Wu, Z.; Ouyang, Z. Changes of cultivated land function in China since 1949. Acta Geogr. Sin. 2014, 69, 435-447. (In Chinese)

9. Lovell, S.T. Multifunctional Urban Agriculture for Sustainable Land Use Planning in the United States. Sustainability 2010, 2, 2499-2522. [CrossRef]

10. Zhou, L. Study on the Value of Multi-Functional Protection of Cultivated Land in Process of Urbanization: A Case of Ningbo. PHD. Thesis, Zhejiang University, Hangzhou, China, 2010. (In Chinese).

11. Deng, X.; Li, Z.; Gibson, J. A Review on Trade-Off Analysis of Ecosystem Services for Sustainable Land-Use Management. J. Geogr. Sci. 2016, 26, 953-968. [CrossRef]

12. Tan, S.; Zhang, H. Performance Evaluation on the Policies of Cultivated Land Protection in China from the Perspective of Quantity Protection. China Popul. Resour. Environ. 2010, 20, 153-158. (In Chinese)

13. Hengsdijk, H.; Meijerink, G.W.; Mosugu, M.E. Modeling the effect of three soil and water conservation practices in Tigray, Ethiopia. Agric. Ecosyst. Environ. 2005, 105, 29-40. [CrossRef]

14. Lynch, L.; Musser, W.N. A Relative Efficiency Analysis of Farmland Preservation Programs. Land Econ. 2001, 77, 577-594. [CrossRef]

15. Gaaff, A.; Reinhard, S. Incorporating the value of ecological networks into cost-benefit analysis to improve spatially explicit land-use planning. Ecol. Econ. 2012, 73, 66-74. [CrossRef]

16. Jongeneel, R.; Polman, N.; Slangen, L. Land Use Policy Corrigendum to "Cost-benefit analysis of the Dutch nature policy: Transaction costs and land market impacts". Land Use Policy 2013, 31, 660. [CrossRef]

17. Jahanifar, K.; Amirnejad, H.; Azadi, H.; Adenle, A.A.; Scheffran, J. Land Use Policy Economic analysis of land use changes in forests and rangelands: Developing conservation strategies. Land Use Policy 2019, 88, 104003. [CrossRef]

18. Yu, L.; Cai, Y. Performance Evaluation and Obstacle Indicator Diagnoses of Economic Compensation for Farmland Protection Policy Based on Farmers' Satisfaction. J. Nat. Resour. 2015, 30, 1093-1103. (In Chinese)

19. Xie, J.; Cai, Y. Dynamic Response Relation Between Farmers' Livelihood Assets and Farmland Protection Compensation Policy Effects. China Land Sci. 2017, 31, 15-23. (In Chinese)

20. Cortignani, R. Green Payment and Perceived Rural Landscape Quality: A Cost-Benefit Analysis in Central Italy. Sustainability 2018, 10, 2910. [CrossRef] 
21. Zasada, I.; Fertner, C.; Piorr, A.; Nielsen, T.S. Peri-urbanisation and multifunctional adaptation of agriculture around Copenhagen. Dan. J. Geogr. 2011, 111, 59-72. [CrossRef]

22. Lalla-Ruiz, E.; Expósito-Izquierdo, C.; Melián-Batista, B.; Moreno-Vega, J.M. A Set-Partitioning-based model for the Berth Allocation Problem under Time-Dependent Limitations. Eur. J. Oper. Res. 2016, 250, 1001-1012. [CrossRef]

23. Dulebenets, M.A. Green vessel scheduling in liner shipping: Modeling carbon dioxide emission costs in sea and at ports of call. Int. J. Transp. Sci. Technol. 2018, 7, 26-44. [CrossRef]

24. Xiang, X.; Liu, C.; Miao, L. Reactive strategy for discrete berth allocation and quay crane assignment problems under uncertainty. Comput. Ind. Eng. 2018, 126, 196-216. [CrossRef]

25. Rachwan, R.; Abotaleb, I.; Elgazouli, M. The Influence of Value Engineering and Sustainability Considerations on the Project Value. Procedia Environ. Sci. 2016, 34, 431-438. [CrossRef]

26. Bock, S.; Pütz, M. Implementing Value Engineering based on a multidimensional quality- oriented control calculus within a Target Costing and Target Pricing approach. Int. J. Prod. Econ. 2017, 183, 146-158. [CrossRef]

27. Ibusuki, U.; Kaminski, P.C. Product development process with focus on value engineering and target-costing: A case study in an automotive company. Int. J. Prod. Econ. 2007, 105, 459-474. [CrossRef]

28. Park, C.; Kim, H.; Park, H.; Goh, J.; Pedro, A. ScienceDirect BIM-based idea bank for managing value engineering ideas. Int. J. Proj. Manag. 2017, 35, 699-713. [CrossRef]

29. Tohidi, H. Procedia Computer Review the benefits of using Value Engineering in Information Technology Project Management. Procedia Comput. Sci. 2011, 3, 917-924. [CrossRef]

30. Qiu, Y. Study on the Eco-tourism Resource Evaluation Based on the Value Engineering: A Case Study of Lishui, Zhejiang Province. J. Nat. Resour. 2009, 24, 2158-2168. (In Chinese)

31. El-Nashar, W.Y. Effect of drains coverings on environment by using value engineering. Alex. Eng. J. 2017, 56, 327-332. [CrossRef]

32. Fang, Y.; Rau, H. Optimal Consumer Electronics Product Take-Back Time with Consideration of Consumer Value. Sustainability 2018, 9, 385. [CrossRef]

33. Wiggering, H.; Dalchow, C.; Glemnitz, M.; Helming, K.; Müller, K.; Schultz, A.; Stachow, U.; Zander, P. Indicators for multifunctional land use-Linking socio-economic requirements with landscape potentials. Ecol. Indic. 2006, 6, 238-249. [CrossRef]

34. Brandão, M.; Clift, R.; Canals, L.M.I.; Basson, L. A Life-Cycle Approach to Characterising Environmental and Economic Impacts of Multifunctional Land-Use Systems: An Integrated Assessment in the UK. Sustainability 2010, 2, 3747-3776. [CrossRef]

35. Xie, G.; Zhen, L.; Zhang, C.; Deng, X.; Koenig, H.J. Assessing the Multifunctionalities of Land Use in China. J. Resour. Ecol. 2010, 1, 311-318. [CrossRef]

36. Wang, Q.; Yuan, X.; Ma, C. Research on the impact assessment of urbanization on air environment with urban environmental entropy model: A case study. Stoch. Environ. Res. Risk Assess. 2012, 26, 443-450. [CrossRef]

37. Wang, Q.; Yuan, X.; Zhang, J.; Gao, Y.; Hong, J.; Zuo, J.; Liu, W. Assessment of the Sustainable Development Capacity with the Entropy Weight Coefficient Method. Sustainability 2015, 7, 13542-13563. [CrossRef]

38. Yong, X.; Zhang, A. Study on Economic Compensation Standard for Peasant Households in Cultivated Land Preservation Based on Opportunity Cost. Res. Agric. Mod. 2011, 32, 606-610. (In Chinese)

39. Yu, L. Introducing a Simple Method to Calculate Curve of the Best Suitable Region in Value Engineering. 1985. Available online: https://kns.cnki.net/KCMS/detail/detail.aspx?dbcode= CJFQ\&dbname=CJFD8589\&filename=JSJI198506011\&v=MDA3NzBacUZDbmxWN3ZQTHo3Qlo3S3hGdFRNc Vk5RVpZUjhlWDFMdXhZUzdEaDFUM3FUcldNMUZyQ1VSTE91WnU= (accessed on 6 November 2019). (In Chinese).

40. United Nations Department of Economic and Social Affairs. Population Division. World Population Ageing; United Nations: New York, NY, USA, 2015.

41. Yang, X.; Cai, Y.; Zhang, A.; Yu, L.L. Spatial Differences of Farmland Eco-Surplus/deficit and Its regional Equilibrium Mechanism-Based on the Ecological Account of Wuhan Metropolitan Circle. China Popul. Resour. Environ. 2013, 23, 57-64. (In Chinese) 
42. Hu, W.; Zhu, Q.; Zhang, A.; Karnwie, G.A.; Li, J. Impacts of Multifunctional Farmland on Agricultural Economic Growth at County-Level from the Perspective of Quantity and Structure: Evidence from Hubei Province. China Land Sci. 2018, 32, 62-70. (In Chinese)

43. Stürck, J.; Verburg, P.H. Multifunctionality at What Scale? A Landscape Multifunctionality Assessment for the European Union Under Conditions of Land Use Change. Landsc. Ecol. 2017, 32, 481-500. [CrossRef]

(C) 2019 by the authors. Licensee MDPI, Basel, Switzerland. This article is an open access article distributed under the terms and conditions of the Creative Commons Attribution (CC BY) license (http://creativecommons.org/licenses/by/4.0/). 